\title{
Research on Optimization of Key Areas of Drainage Borehole Sealing in Ultrathick Coal Seam
}

\author{
Xin Guo $\mathbb{D}^{D},{ }^{1}$ Sheng Xue $\mathbb{D},{ }^{1}$ Yaobin Li $\mathbb{D},{ }^{1}$ Chunshan Zheng $\mathbb{D},{ }^{1}$ and Linfang Xie ${ }^{2}$ \\ ${ }^{1}$ School of Safety Science and Engineering, Anhui University of Science \& Technology, Huainan 232001, China \\ ${ }^{2}$ Henan Provincial Communications Planning \& Design Institute Co Ltd., Zhengzhou 450052, Henan, China \\ Correspondence should be addressed to Xin Guo; guoxin190510@163.com
}

Received 22 January 2021; Revised 12 February 2021; Accepted 1 March 2021; Published 10 March 2021

Academic Editor: Feng Du

Copyright $\left({ }_{0} 2021\right.$ Xin Guo et al. This is an open access article distributed under the Creative Commons Attribution License, which permits unrestricted use, distribution, and reproduction in any medium, provided the original work is properly cited.

Gas drainage is an important means of gas control. The influence of the key position of the sealing hole on gas drainage was studied by theoretical and numerical simulation combined with field measurement to solve low gas concentration in gas predrainage boreholes in coal mines of China. By analyzing the distribution of cracks around the boreholes and the law of air leakage and simulating the drainage effect of different sealing areas $(8 \mathrm{~m}, 12 \mathrm{~m}$, and $16 \mathrm{~m})$, it was proposed that the key position of the sealing hole should be in the prepeak stress concentration area. According to the actual situation of Baode Mine, the sealing test scheme of different sealing areas was put forward, and the field test was carried out to obtain the key sealing area of gas predrainage boreholes in Baode Mine. Research shows that when the sealing area is $8-16 \mathrm{~m}$, the average gas concentration is $63.57 \%$, and the average pure gas flux is $0.408 \mathrm{~m}^{3} / \mathrm{min}$. The sealing effect of this area is better, with fewer cracks, than that of the existing sealing area, effectively preventing gas leakage and increasing the gas concentration and gas scalar.

\section{Introduction}

Coal, as China's main energy, is vital for China's economy. However, the mining process is faced with production unsafety, especially coal mine gas disasters $[1,2]$. Coal mine gas drainage is an important measure to reduce mine gas emission and prevent spontaneous combustion in goaf [3-6], gas explosion, and gas outburst disasters [7-9]. In China, coal mine gas drainage efficiency is generally low, negative pressure is relatively low, the borehole drainage cycle is short, and the drainage effect is unsatisfying [10]. Gas supply capacity is insufficient due to the reduction of gas content in the borehole $[11,12]$. During gas drainage, the air infiltration on one side of the roadway causes a low gas drainage concentration due to the poor sealing effect of the borehole $[13,14]$.

The sealing section should be compacted and dense to avoid gas leakage [15]. If the low permeability of the sealing section cannot be guaranteed, the channel of gas seepage and external air inhalation will be produced. Damages to the seal will also cause leakage of the sealing medium. The key to borehole sealing is to seal the cracks in the surrounding rock of the borehole. Field practice shows that the sealing effect is ensured only when the borehole sealing material enters the pores and microcracks around the borehole. Therefore, the microscopic characteristics of the borehole sealing section and its sealing performance to the surrounding rock fissure zone of the borehole are the main factors affecting the sealing effect of the borehole, and it is the concentrated embodiment of the borehole sealing mechanism $[16,17]$. As the borehole will creep due to the in situ stress, the surface of the borehole seal is in the micromotion state, which challenges the borehole seal. As the boreholes are affected by the time effect, the surrounding rock stress caused by coal mining and other disturbances is repeatedly pressed so that the cracks around the borehole are continuously generated, crossed, and connected and the difficulty of borehole sealing lies in timely sealing of these new cracks $[18,19]$. As the porosity of coal is the main place for gas enrichment, and the fracture in coal rock is the main channel for gas migration, the development degree and distribution characteristics of 
porosity and fracture in coal reservoir directly affect the adsorption, desorption, diffusion, and permeability of gas in coal rock and then affect the extraction of coal seam gas [20-23]. Borehole instability deformation also impacts gas drainage. Most gas drainage boreholes in coal seam can drill more than 200 meters, and the sealing length is generally 10-15 meters, and the length of the extraction gas chamber is more than 185 meters. The collapse of the borehole wall in any part of the 100-meter borehole will cause the limited length of the borehole to decrease, and the actual utilization rate of gas is low. The borehole, especially that in the soft coal seam with high gas content and low permeability, is often abandoned due to the collapse and blockage of a certain borehole, which makes the coal seam have a blank zone of gas extraction, resulting in potential coal and gas outburst $[24,25]$. The mining depth of coal mines in China is extending at the speed of 8-12 $\mathrm{m}$ per year and is estimated to reach $1000 \mathrm{~m}$ to $1500 \mathrm{~m}$ in the next 20 years. The surrounding rock of the roadway is deforming at a high speed. More and more serious borehole collapse and deformation are challenging gas drainage and putting forward higher requirements [26, 27].

The reserves of thick-ultrathick coal seams account for more than $45 \%$ of my country's total coal reserves. In the future, it will become an important direction for the development of Chinese coal industry. From the perspective of coal mining, the thickness of the mined coal seam can be divided into 5 thickness levels, of which the thickness of the coal is greater than $8 \mathrm{~m}$, which is called suerthick coal. The $8 \#$ coal seam of Baode Mine is located above the S3 sandstone at the bottom of Shanxi Formation (P1S). The coal thickness varies from 2.15 to $10.50 \mathrm{~m}$, with an average of $7.36 \mathrm{~m}$. The maximum thickness of pure coal is $9.20 \mathrm{~m}$; it belongs to thick-to-ultrathick coal seams. At Baode Mine, the sealing length used in the bedding drilling is $0-8 \mathrm{~m}$ as required by the state. The extraction concentration is low, which is not conducive to the safe production of Baode Mine. In order to solve the problem of low gas drainage rate in Baode Mine, it also provides technical support for gas treatment in other thick-superthick coal seams. We adopted a combination of theoretical simulation and field experiments to find out the key positions of the sealing holes in Baode Mine and improve the sealing efficiency. Previous studies have focused on the impact of borehole spacing [28], borehole length [29], and borehole time [30] on the drainage effect, and the influences of sealing hole position on the borehole are rarely studied. Moreover, the mining conditions of coal seams in China are quite different. The sealing area of gas drainage borehole of a specific coal mine needs to be studied [31]. To give full play to the drainage effect of the gas drainage system, this study, based on the coal deposit conditions and mining conditions of Baode Coal Mine, the concept of key positions of the hole sealing was put forward, analyzed the distribution of coal wall fractures and the gas leakage and seepage law zone around the borehole, and proposed sealing test plan for different sealing areas. And, the position of the leaking gas was accurately found to seal the hole. Field tests were carried out in the 81310 return airway of Baode Coal Mine, and the variation laws of the extraction concentration and gas purity of the extraction borehole in different sealing areas were analyzed. Through comparative analysis, the optimal sealing area of the gas predrainage borehole in Baode Coal Mine was obtained, which not only saves costs but also improves the concentration of drilling.

\section{Project Profile}

The study area is the return airway of 81310 coal mining panel in the third panel of Baode Coal Mine. No large-scale faults, folds, and collapse columns have been found. The $8 \#$ coal seam is located above the S3 sandstone at the bottom of the Shanxi Formation (P1S), and the coal thickness varies from 2.15 to $10.50 \mathrm{~m}$, with an average of $7.36 \mathrm{~m}$. The thickness of pure coal is $1.85-9.20 \mathrm{~m}$, with an average of $6.02 \mathrm{~m}$; they are thick-to-extrathick coal seams, mainly thick coal seams. The structure of the coal seam is complex, containing 0 8 layers of gangue, and the total thickness of the gangue is $0 \sim 3.84 \mathrm{~m}$, with an average of $1.38 \mathrm{~m}$. The direct roof of the coal seam is mostly sandy mudstone and mudstone, and the part is coarse sandstone. The floor is mainly mudstone, followed by siltstone. The thickness variation coefficient of $8 \#$ coal seam is $27.5 \%$. The main coal seam includes a thick coal seam and an extrathick coal seam and gradually becomes thicker from east to west. The extrathick coal seam is distributed in the northwest and southeast of the mining area, and the medium-thick coal seam is in the northern boundary of the mining area.

\section{High-Efficiency Sealing Principle of Borehole}

3.1. Fracture Field Distribution around the Borehole. A longer extraction time usually results in reduced gas concentration and poor tightness as the poor sealing effect allows the air in the roadway to enter the extraction borehole. In addition to the nonstandard operation of the sealing process, the broken coal wall of the roadway and the leakage circle around the borehole also lead to air entry in the roadway [32]. During roadway excavation, the coal wall on both sides of the roadway is affected by mining, which will produce cracks and form air leakage channels. Under the action of negative pressure, the air in the roadway enters the borehole. Affected by the vibration of the drilling process, the coal seam will also be deformed and destroyed, resulting in cracks and loose zones, which are called "air leakage circles" because of the annular shape [33-35], as shown in Figure 1. The loose zone results in a poor sealing effect.

3.2. Gas Leakage Law of Borehole. As the borehole of coal seam is constructed on the side of the roadway, the gas leakage and seepage characteristics of the borehole are inevitably affected by the stress changes around the roadway [36]. It can be seen from Figure 2 that the three-dimensional stress $\left(\sigma_{x}, \sigma_{y}, \sigma_{z}\right)$ at the wall of the roadway are removed to varying degrees. With the increase of the distance from the roadway wall, $\sigma_{x}$ gradually reaches the original stress value and $\sigma_{y}$ and $\sigma_{z}$ first experience stress concentration and then gradually return to the original stress value. The stress concentration of $\sigma_{z}$ is much higher than that of $\sigma_{y}$. 


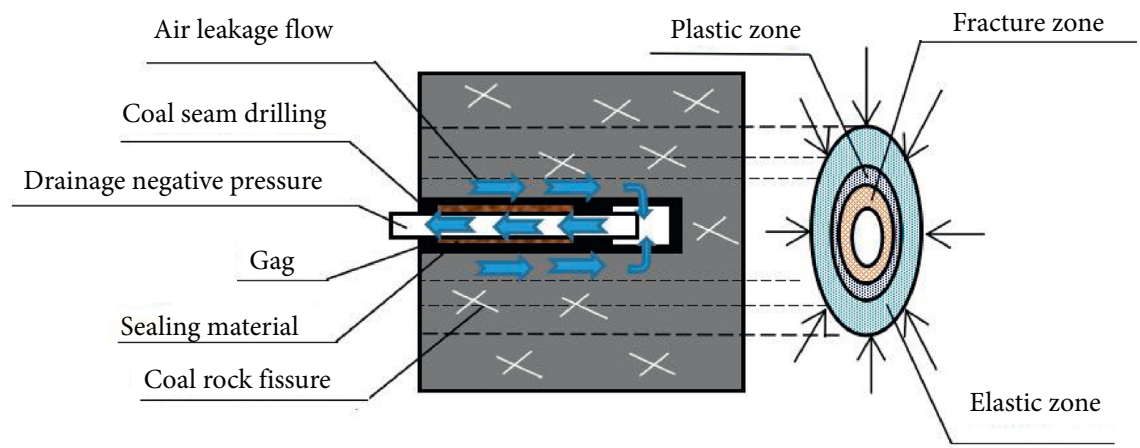

Figure 1: Air leakage schematic diagram of borehole broken coal rock.

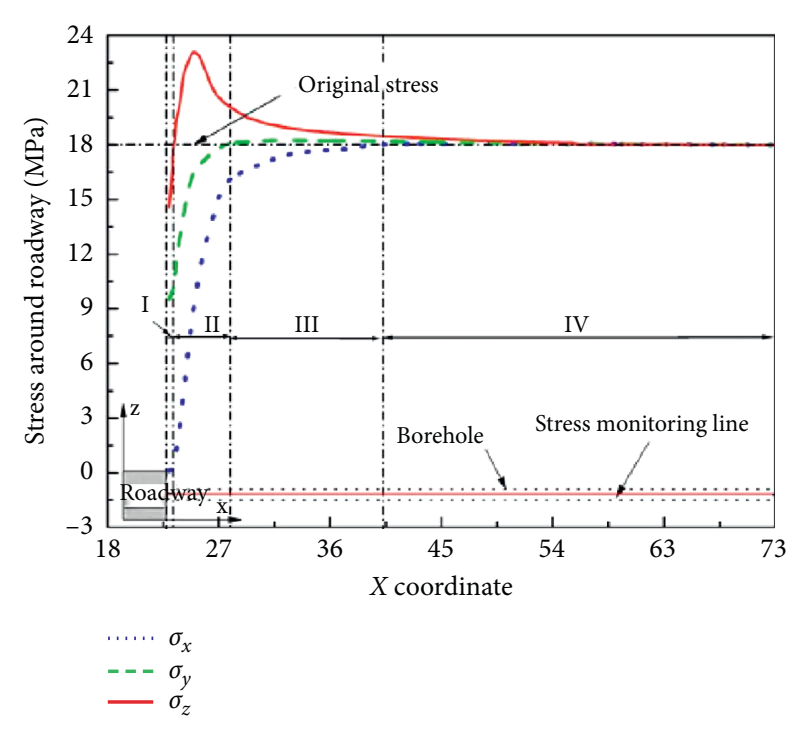

Figure 2: Distribution of stress field induced by roadway excavation.

According to different pressure relief states of $\sigma_{x}, \sigma_{y}$, and $\sigma_{z}$, the surrounding of the roadway can be divided into four different stress regions (I to IV). In region I, $\sigma_{x}, \sigma_{y}$, and $\sigma_{z}$ are all relieved, and each stress reaches the minimum. In regions II and III, $\sigma_{x}$ and $\sigma_{y}$ increase continuously, and $\sigma_{z}$ experiences a large stress concentration, whose peak value is 1.3 times of the original stress value. In stress region IV, the three-dimensional stress approaches the original stress.

The four air leakage areas are shown in Figure 3. In stress region $I$, the stress redistribution caused by roadway excavation makes $\sigma_{x}, \sigma_{y}$, and $\sigma_{z}$ experience a large stress release, and all the crack openings increase. The permeability of this area is the largest, and the air easily flows into the borehole through the surrounding cracks. Stress area I is the free air leakage area (FAA). In stress region II, except that the two concentrated stresses on both sides of $\sigma_{y}$ and $\sigma_{z}$ on the upper and lower sides lead to the decrease of permeability around the borehole $\sigma_{x}, \sigma_{y}$, and $\sigma_{z}$ around the borehole which are almost effectively released. Stress region II is likely to have air leakage and can be defined as a semifree air leakage region (SAA). Due to the high compressive stress in SAA and the closure of cracks, the severity of air leakage in SAA is lower than that in FAA. In stress region III, $\sigma_{y}$ and $\sigma_{z}$

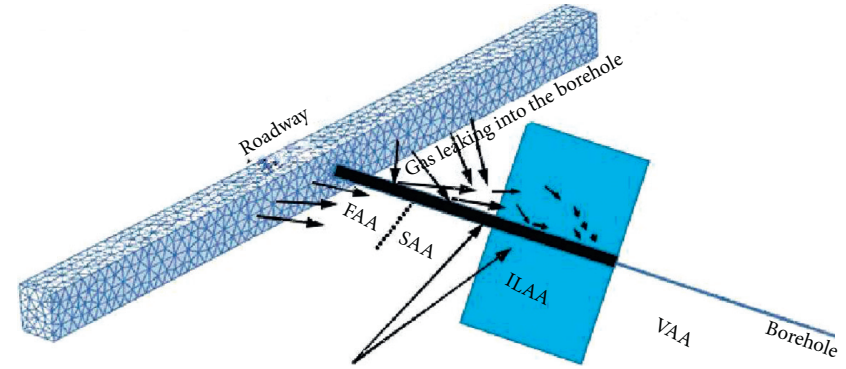

Figure 3: Distribution of air leakage areas around the roadway.

increase after roadway excavation, while $\sigma_{x}$ is slightly released. The three stresses around the borehole are generally large, especially $\sigma_{y}$ on the upper and lower sides of the borehole and $\sigma_{z}$ on the left and right sides. Stress area III almost has no air leakage and can be described as a hard-toair leakage area (HAA). In stress zone IV, the coal seam is not affected by roadway excavation. Because of the small diameter of the borehole, the changes in $\sigma_{x}, \sigma_{y}$, and $\sigma_{z}$ caused by the borehole are relatively limited. The stress distribution in this area is very close to the original stress, and the coal permeability is almost at the original state and is higher than that of HAA. Stress area IV can be called the original air leakage area (VAA). Since VAA is far from the ventilation roadway, the air leakage driven by pressure difference is weaker than that in regions I-III.

As FAA and SAA have higher permeability than the other two areas and are adjacent to the roadway, gas leakage is more likely to occur there. The sealing section should exceed FAA and SAA (the length is about $8 \mathrm{~m}$ ) to form a leak-proof area composed of HAA sections (length $8 \mathrm{~m}$ ) to effectively prevent air leakage. In this case, the leaked air cannot flow into the borehole through cracks in FAA, SAA, and HAA sections, and because of the low permeability value of HAA, only a few air leakages go into the borehole in the VAA area, as shown by the blue arrow. Therefore, the sealing position of 8-16 $\mathrm{m}$ can generally achieve efficient extraction of gas in Baode Mine.

\subsection{Simulation of Different Sealing Position in Borehole}

3.3.1. Governing Equation of Gas Transport. The coal fissures cut the coal into matrix units, and the adsorbed gas in the 
coal matrix acts as a gas source, constantly replenishing the gas that is reduced by being pumped out. This paper simplifies the gas flow into a series process and only considers the change of fracture permeability:

$$
Q_{s}=a D\left(c_{m}-c_{f}\right)=\frac{1}{\tau}\left(c_{m}-c_{f}\right),
$$

where $Q_{s}$ represents the mass exchange rate per unit volume of coal matrix and fracture system, $a$ is the matrix form factor, $D$ denotes the gas diffusion coefficient, $c_{m}$ is the gas concentration in coal matrix, $c_{f}$ is the gas concentration in coal fracture system, $\tau$ is the adsorption time derived from the conservation of mass:

$$
\frac{\partial m_{m}}{\partial t}=-\frac{M_{g}}{\tau R T}\left(p_{m}-p_{f}\right)
$$

where $m_{m}$ represents the total mass of gas in the coal matrix per unit volume, $M_{g}$ is the gas molecular mass, $R$ is the universal gas constant, and $T$ is the coal seam temperature. The total mass of gas in the coal matrix per unit volume is

$$
m_{m}=\phi_{m} \frac{M_{g}}{R T} p_{m}+\left(1-\phi_{m}\right) \rho_{n} \rho_{c} \frac{V_{L} p_{m}}{p_{m}+P_{L}},
$$

where $\rho_{n}$ represents the gas density under standard conditions, $\rho_{c}$ is the false density of coal, $V_{L}$ is the Langmuir volume constant, and $P_{L}$ is the Langmuir pressure constant. The gas density is

$$
\rho_{n}=\frac{M_{g}}{V_{M}} .
$$

Putting formulas (3) and (4) into formula (2), we get

$$
\left[\phi_{m}+\left(1-\phi_{m}\right) \frac{\rho_{c} V_{L} P_{L} R T}{V_{M}\left(p_{m}+P_{L}\right)^{2}}\right] \frac{\partial p_{m}}{\partial t}=-\frac{1}{\tau}\left(p_{m}+p_{f}\right) .
$$

3.3.2. Initial Conditions and Boundary Conditions. For the coal deformation equation, the boundary conditions of displacement and stress can be defined as

$$
\begin{aligned}
u_{i} & =\widetilde{u}_{i}(t), \\
\sigma_{i j} n_{j} & =\widetilde{F}_{i}(t) .
\end{aligned}
$$

The initial conditions of gas flow can be expressed as

$$
\begin{aligned}
& P_{m}(0)=P_{m 0}, \\
& P_{f}(0)=P_{f 0},
\end{aligned}
$$

where $P_{m 0}$ represents Initial matrix gas pressure and $P_{f 0}$ represents Initial fracture gas pressure.

The gas flow process in the process of gas drainage is calculated, and the coefficient partial differential equation is

$$
e_{a} \frac{\partial^{2} u}{\partial t^{2}}+d_{a} \frac{\partial u}{\partial t}-\Delta \cdot(c \Delta u+\alpha u-\gamma)+\beta \cdot \Delta u+a u=f
$$

Bring formula (5) into formula (8),

$$
\left\{\begin{array}{l}
u=p_{m}, \\
e_{a}=c=\alpha=\beta=\gamma=a=0, \\
d_{a}=\phi_{m}+\left(1-\phi_{m}\right) \frac{\rho_{c} R T V_{L} P_{L}}{V_{M}\left(p_{m}+P_{L}\right)}, \\
f=-\frac{1}{\tau}\left(p_{m}-p_{f}\right) .
\end{array}\right.
$$

Taking the actual situation of the roadway head in the third panel 81310 of Shenhua Shendong Baode Mine as the background, a gas drainage model along the bedding long borehole is established according to onsite parameters through the Comsol simulation software, as shown in Figure 4. The length and width of the model are $260 \mathrm{~m}$ and $150 \mathrm{~m}$, respectively. The gas pressure of the coal body is $2.5 \mathrm{MPa}$, the suction pressure is $13 \mathrm{kPa}$, and the permeability is $3.85 \mathrm{md}$. The simulation object is a group of 10 parallel boreholes, which are constructed in the 81310 coal mining panel along the trough. The borehole length is $200 \mathrm{~m}$, and the borehole spacing is $10 \mathrm{~m}$. Under the same extraction time, negative pressure, borehole spacing, borehole length, coal permeability, and gas pressure, the effects of different sealing lengths on gas extraction are simulated and analyzed.

During the excavation of the coal seam roadway, the equilibrium state of the gas pressure in the coal seam and the matrix gas pressure is destroyed. The fractured gas in the pressure relief zone gradually gushes out into the roadway, and the gas pressure in the coal seam is redistributed to form the natural gas emission zone of the roadway. The natural gas emission zone of the coal seam roadway significantly influences the gas drainage of the coal seam along the borehole. Figure 5 shows the gas pressure distribution of three plugging lengths $(8 \mathrm{~m}, 12 \mathrm{~m}$, and $16 \mathrm{~m})$ after 800 days of drainage. It can be seen that, as the length of the borehole sealing increases, the scope of influence of drainage gradually increases, and the gas pressure drops fast. The sealing length can be determined according to the actual situation, combined with the extraction effect and cost factors.

\section{Field Test}

4.1. Test Scheme. Boreholes were constructed in the No. 81310 return airway. Five boreholes were constructed in each group with a spacing of $5 \mathrm{~m}$, and each group borehole spacing is $20 \mathrm{~m}$. The schematic diagram of drilling arrangement layout is shown in Figure 6. According to the parameters such as permeability coefficient of the coal seam, the influence of certain fractures was considered. During gas drainage borehole sealing, "bag type two plugging one injection" sealing method was used [37]. In the sealing position, the sealing positions of $0-8 \mathrm{~m}, 0-12 \mathrm{~m}, 8-16 \mathrm{~m}$, and $0-16 \mathrm{~m}$ are adopted, which correspond to the first group, the second group, the third group, and the fourth group in Figure 6, respectively. The sealing tests were carried out with these combinations, 

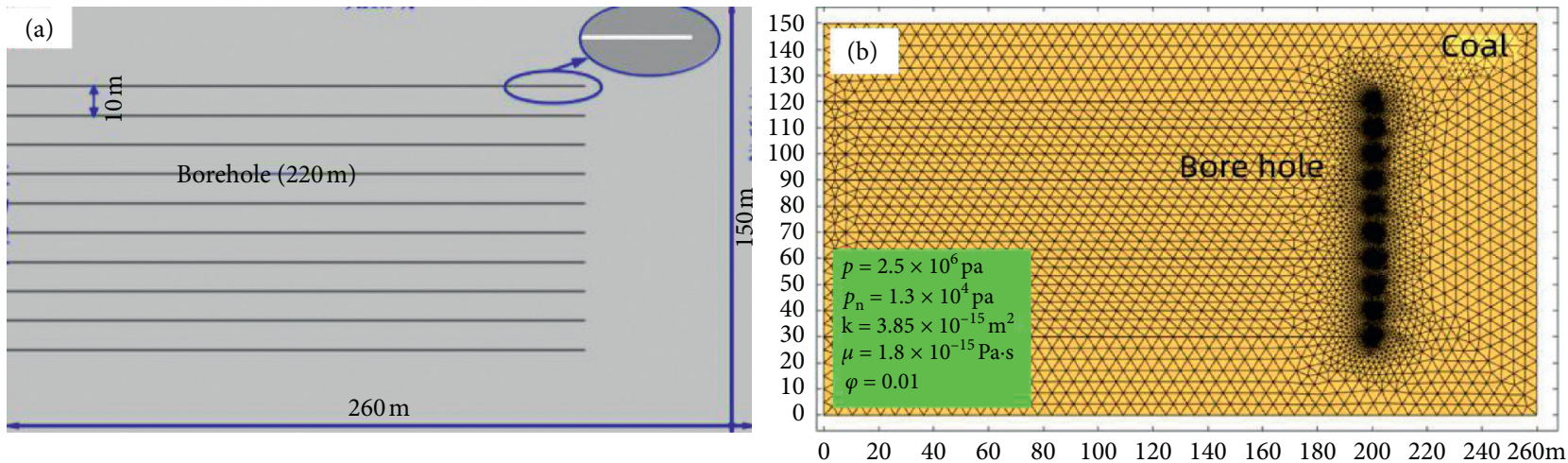

Figure 4: Distribution of air leakage areas around the roadway. (a) Geometric shape and size. (b) Mesh subdivision.
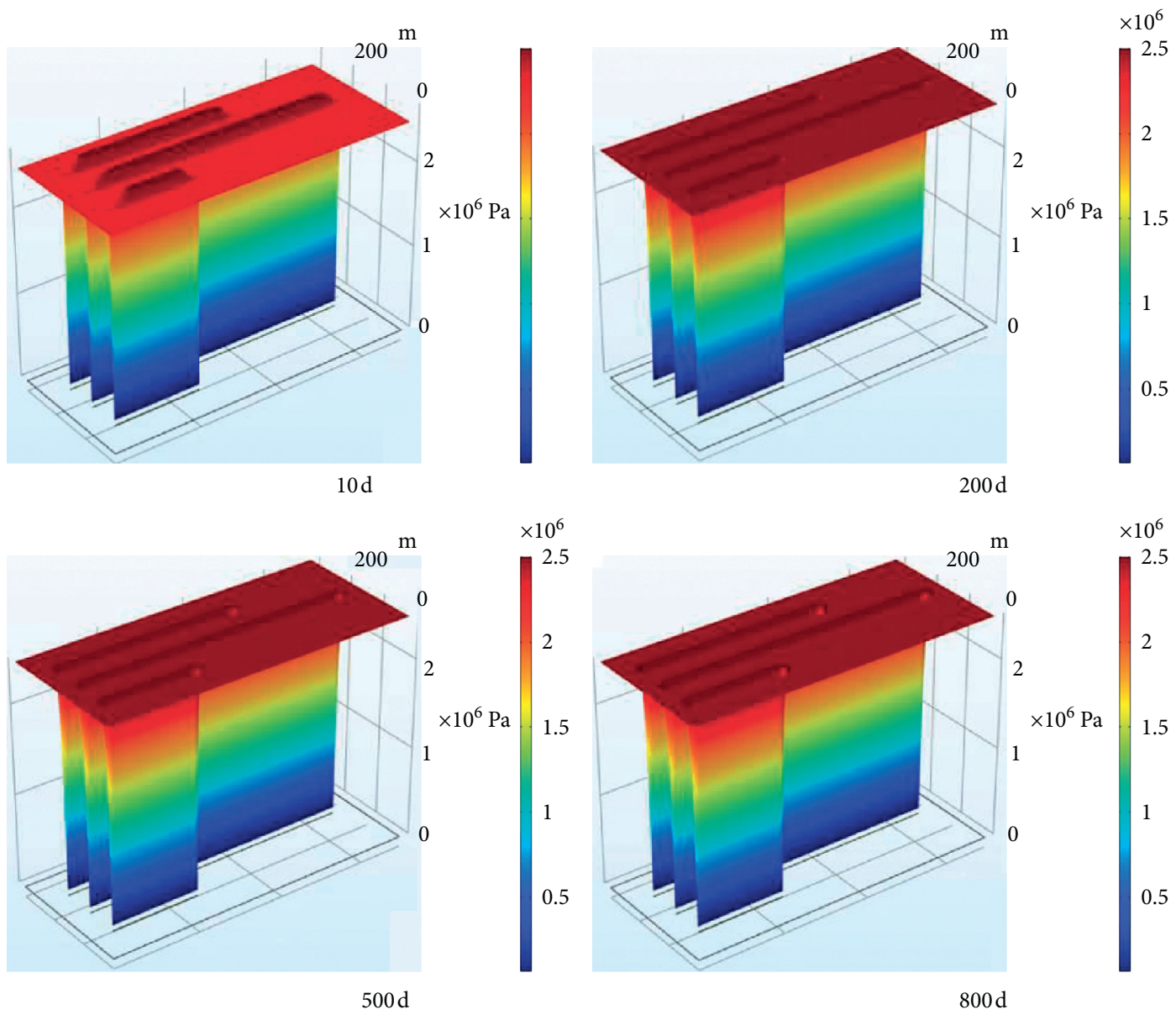

FIGURE 5: Gas pressure distribution during gas drainage under different sealing lengths.

and the gas concentration and pure gas flux of each sealing method were monitored. By analyzing and comparing the drilling data, the optimal sealing area was determined.

4.2. Test Results and Analysis. According to the test data, analyze the gas concentration graph (Figure 7) and the curve of pure gas flux (Figure 8) over time after the four sets of borehole.
4.2.1. Mixed Gas Concentration. It can be seen from Figure 7 that, during the drainage, the average gas concentration of the four groups of boreholes is $48.7 \%, 39.32 \%, 63.57 \%$, and $58.37 \%$, respectively. The mixed gas concentration of the third group is 1.31 times that of the first group, 1.62 times that of the second group, and 1.09 times of the fourth group. In addition, the mixed gas concentration of the four groups all shows a downward trend. It can also be seen that the mixed gas concentration of the third group drops from $93 \%$ to $56.4 \%$, but 


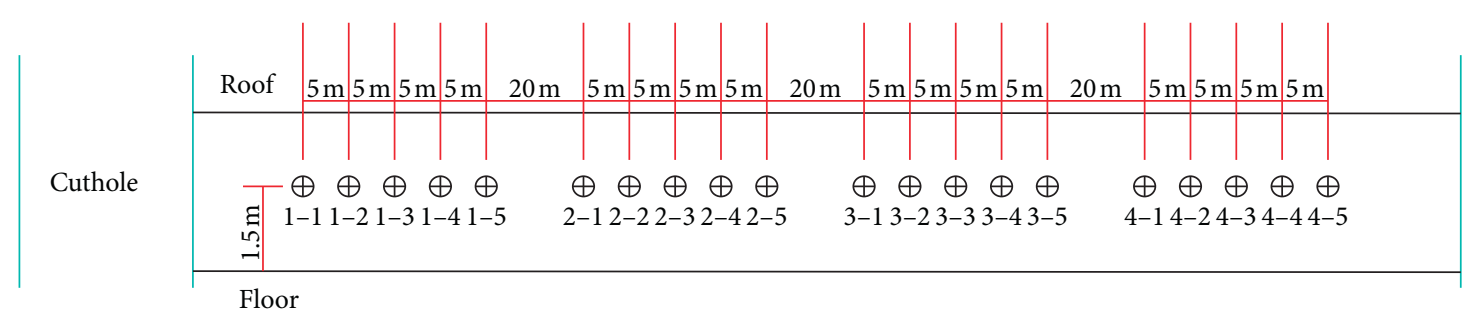

Figure 6: Diagram of hole sealing.

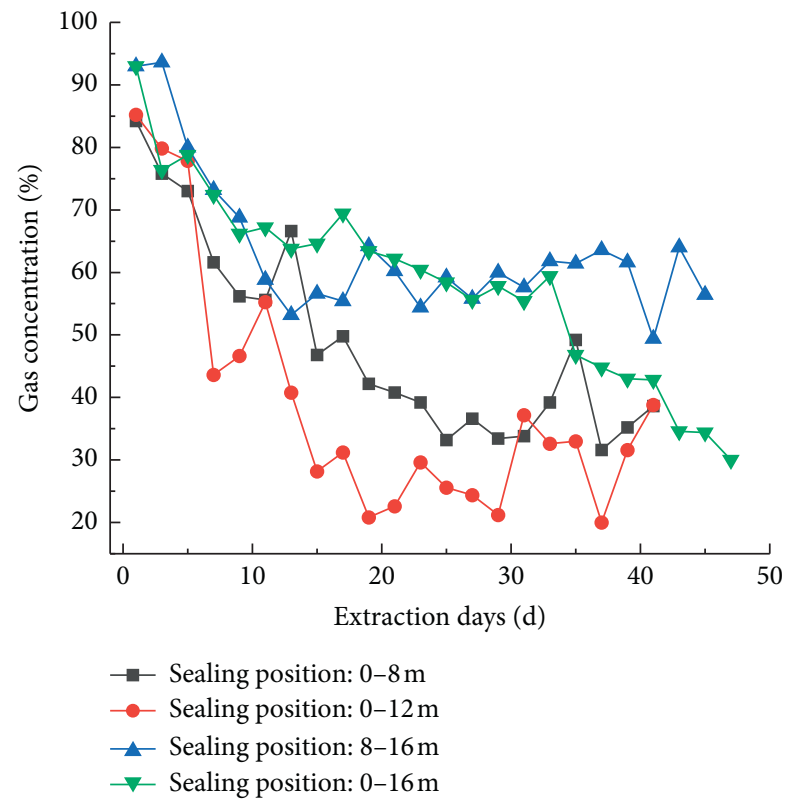

Figure 7: Curve of borehole gas concentration changing with time.

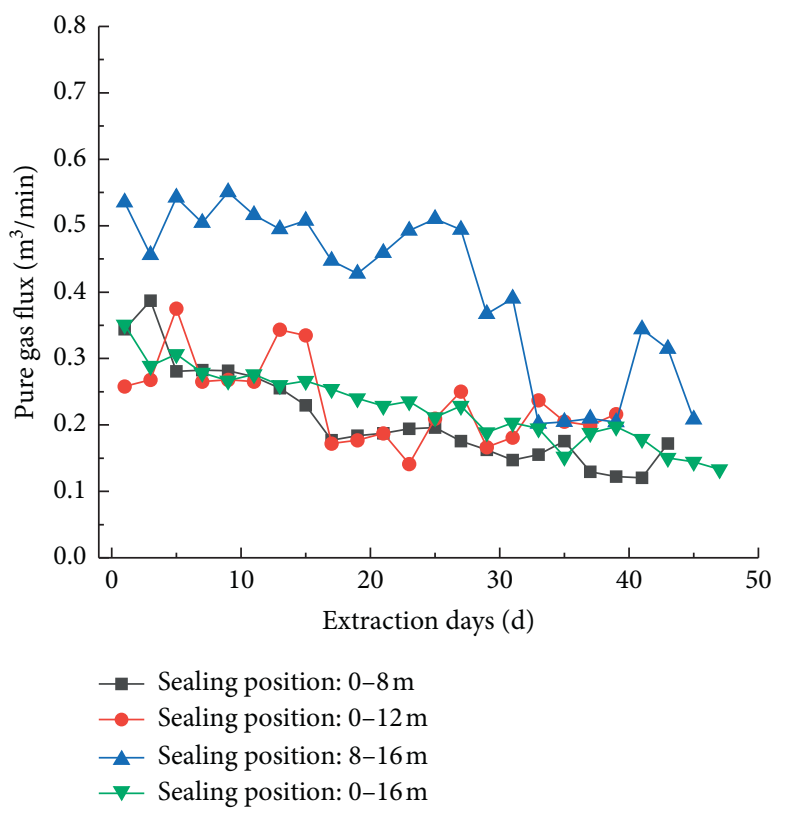

FIgUre 8: Curve of pure gas flux changing with time in the borehole. still maintains at a higher concentration. The concentration of mixed gas in the other three groups decreases significantly. During the extraction, the concentration of mixed gas in the first group, the second group, and the fourth group decreases by $45.6 \%, 46.4 \%$, and $63 \%$, respectively.

It is found that the concentration of mixed gas in the first group and the second group decreases rapidly and fails to maintain at a high level, indicating that the leakage of boreholes in the sealing area of $0-8 \mathrm{~m}$ and $0-12 \mathrm{~m}$ is very serious. The mixed gas concentration of the fourth group is higher than that of the first group and the second group, indicating that the porosity in the sealing area of $0-16 \mathrm{~m}$ is lower than that in the area of $0-8 \mathrm{~m}$ and $0-12 \mathrm{~m}$. The $8-16 \mathrm{~m}$ sealing area has the highest mixed gas concentration, proving that the pores are not developed in this interval and this area is suitable for sealing.

4.2.2. Pure Gas Flux. It can be seen from Figure 8 that, during the drainage, the pure gas flux of the four groups is $0.2106 \mathrm{~m}^{3} / \mathrm{min}, \quad 0.2361 \mathrm{~m}^{3} / \mathrm{min}, \quad 0.408 \mathrm{~m} 3 / \mathrm{min}$, and $0.226 \mathrm{~m}^{3} / \mathrm{min}$. The pure gas flux of the first group, the second group, and the fourth group is only $51.62 \%, 57.87 \%$, and $55.39 \%$ of the third group and increases in turn, indicating that the porosity of boreholes in the area of $0-8 \mathrm{~m}$ to $0-12 \mathrm{~m}$ and then to $0-16 \mathrm{~m}$ decreases gradually.

Through the analysis of the gas concentration and gas scalar of four groups of test predrainage boreholes in the 81310 return airway of Baode Mine, it is found that the loose zone greatly influences the gas flow of predrainage boreholes. Compared with the national standard and the $0-8 \mathrm{~m}$ sealing position used in Baode Mine, the $8-16 \mathrm{~m}$ sealing position has higher gas concentration and purity, slower attenuation and longer borehole life, and is more suitable for sealing.

\section{Conclusions}

(1) According to the research on the crack distribution around the boreholes in 81310 working face, the gas leakage law was studied by COMSOL numerical simulation. When the sealing depth was within the pressure relief zone but beyond the "nonpenetrating zone between fracture and free surface," the pumping effect was better and the stability of the borehole sealing section was better. The optimal sealing range of the drainage borehole in the test area was determined as $8-16 \mathrm{~m}$. 
(2) Through the field test and study on the key position of hole sealing in Baode Mine, the variation rules of gas extraction concentration and pure gas flux at different sealing hole positions were compared. It was found that when the sealing position of the gas extraction borehole in the adjacent layer of Baode Mine was $8-16 \mathrm{~m}$, the average pure gas extraction concentration was $63.57 \%$ and the average pure gas flux was $0.408 \mathrm{~m}^{3} / \mathrm{min}$. Compared with the existing sealing position of $0-8 \mathrm{~m}$, the degree of decrease in the concentration and scalar amount of the extracted gas is the lowest, and a better sealing effect has been achieved. Therefore, it is determined that the best position for the sealing depth of the coal seam in Baode Mine is $8-16 \mathrm{~m}$.

(3) By means of theoretical analysis and numerical simulation, the influence of different sealing position on the effect of borehole gas drainage is obtained. The field test proves that the sealing range of 8-16 m has played a guiding significance for the sealing of boreholes in Baode Coal Mine and provides theoretical and technical support for determining reliable drainage parameters.

\section{Data Availability}

The data used to support the findings of this study are available from the corresponding author upon request.

\section{Conflicts of Interest}

The authors declared no conflicts of interest with respect to the research, authorship, and/or publication of this article.

\section{Authors' Contributions}

All authors contributed to this paper. Xin Guo prepared and edited the manuscript. Xin Guo and Sheng Xue made a substantial contribution to the data analysis and revised the article. Xin Guo, Linfang Xie, and Yaobin Li reviewed the manuscript and processed the investigation during the research process. Sheng Xue and Chunshan Zheng provided financial support.

\section{Acknowledgments}

The authors acknowledge the financial support for this work provided by the National Key Research and Development Program of China (2018YFC0808000), National Natural Science Foundation of China (51904013), Youth Science and Technology Talents Support Program (2020) by Anhui Association for Science and Technology (RCTJ202005), and Open Research Fund of State Key Laboratory of Coal Resources and Safe Mining, CUMT (SKLCRSM20KF003).

\section{References}

[1] L. Yuan and P. S. Zhang, "Development status and prospect of geological guarantee technology for precise coal Mining," Journal of China Coal Society, vol. 44, no. 8, pp. 2277-2284, 2019.
[2] S. Xue and L. Yuan, "The use of coal cuttings from underground boreholes to determine gas content of coal with direct desorption method," International Journal of Coal Geology, vol. 174, pp. 1-7, 2017.

[3] T. Chu, Y. Li, and Y. X. Chen, "Risk assessment of gas control and spontaneous combustion of coal under gas drainage of an upper tunnel," International Journal of Mining Science and Technology, vol. 29, no. 3, pp. 491-498, 2019.

[4] H. Y. Wang, B. Tan, Z. Z. Shao et al., "Influence of different content of FeS2 on spontaneous combustion characteristics of coal," Fuel, vol. 288, Article ID 119582, 2021.

[5] H. Y. Wang, X. Fang, B. Tan et al., "Research and application of the underground fire detection technology based on multidimensional data fusion," Tunnelling and Underground Space Technology, vol. 109, Article ID 103753, 2021.

[6] H. Y. Wang, X. Fang, F. Du et al., “Three-dimensional distribution and oxidation degree analysis of coal gangue dump fire area: a case study," Science of The Total Environment, vol. 772, Article ID 145606, 2021.

[7] H. B. Liu, Y. J. Dong, and F. Z. Wang, "Gas Outburst Prediction Model Using Improved Entropy Weight Grey Correlation Analysis and IPSO-LSSVM," Mathematical Problems In Engineering, vol. 2020, Article ID 8863425, 10 pages, 2020.

[8] K. Wang and F. Du, "Coal-gas compound dynamic disasters in China: a review," Process Safety and Environmental Protection, vol. 133, pp. 1-17, 2020.

[9] S. Lu, L. Li, Y. Cheng, Z. Sa, Y. Zhang, and N. Yang, "Mechanical failure mechanisms and forms of normal and deformed coal combination containing gas: model development and analysis," Engineering Failure Analysis, vol. 80, pp. 241252, 2017.

[10] K. Wang, L. Q. Zhang, D. Xu et al., "Simulation of the extraction efficiency of coalbed methane under water injection: a gas-liquid-solid coupling model," Geofluids, vol. 2020, Article ID 1475316, 14 pages, 2020.

[11] T. J. Zhang, M. K. Pang, X. K. Jiang et al., "Influence of negative pressure on gas percolation characteristics of coal body in perforated drilling hole," Rock and Soil Mechanics, vol. 40, no. 70, pp. 2517-2524, 2019.

[12] Y. P. Cheng, J. Dong, W. Li et al., "Effect of negative pressure on coalbed methane extraction and application in the utilization of methane resource," Journal of China Coal Society, vol. 42, no. 6, pp. 1466-1474, 2017.

[13] W. Qin, J. Xu, and G. Hu, "Optimization of abandoned gob methane drainage through well placement selection," Journal of Natural Gas Science and Engineering, vol. 25, pp. 148-158, 2015.

[14] Y. Y. Cheng, Research on Failure Mechanisms of Gas Drainage through Drilling in Coal Seam and Efficient Sealing Technology, China University of Mining and Technology, Xuzhou, China, 2014.

[15] H. M. Yang, F. K. Ren, Z. F. Wang et al., "Quality inspection and quantitative evaluation method for borehole sealing in gas drainage," Journal of China Coal Society, vol. 44, no. S1, pp. 164-170, 2019.

[16] X. L. Yan, S. H. Zhang, S. H. Tang et al., "Quantitative optimization of drainage strategy of coalbed methane well based on the dynamic behavior of coal reservoir permeability," Scientifc Reports, vol. 10, Article ID 20306, 2020.

[17] J. Fan, P. Liu, J. Li, and D. Jiang, "A coupled methane/air flow model for coal gas drainage: model development and finitedifference solution," Process Safety and Environmental Protection, vol. 141, pp. 288-304, 2020. 
[18] Y. Xue, F. Gao, Y. Gao, X. Liang, Z. Zhang, and Y. Xing, "Thermo-hydro-mechanical coupled mathematical model for controlling the pre-mining coal seam gas extraction with slotted boreholes," International Journal of Mining Science and Technology, vol. 27, no. 3, pp. 473-479, 2017.

[19] C. S. Zheng, H. Li, M. Kizil et al., "Performance enhancement of horizontal underground-to-inseam gas drainage boreholes with double-phase-grouting sealing method for coal mining safety and clean gas resource," Journal of Natural Gas Science and Engineering, vol. 76, Article ID 103179, 2020.

[20] H. Lin, M. Huang, S. Li, C. Zhang, and L. Cheng, "Numerical simulation of influence of Langmuir adsorption constant on gas drainage radius of drilling in coal seam," International Journal of Mining Science and Technology, vol. 26, no. 3, pp. 377-382, 2016.

[21] C. Xin, F. Du, K. Wang et al., "Damage evolution analysis and gas-solid coupling model for coal containing gas," Geomechanics and Geophysics for Geo-Energy and Geo-Resources, vol. 7, no. 1, 2021.

[22] H. J. Guo, H. L. Tang, Y. C. Wu et al., "Gas seepage in underground coal seams: application of the equivalent scale of coal matrix-fracture structures in coal permeability measurements," Fuel, vol. 288, Article ID 119641, 2021.

[23] H. Guo, L. Yuan, Y. Cheng, K. Wang, and C. Xu, "Experimental investigation on coal pore and fracture characteristics based on fractal theory," Powder Technology, vol. 346, pp. 341-349, 2019.

[24] S. Y. Hua, G. C. Hao, G. R. Feng et al., "A method for improving the methane extraction concentrations of in-seam boreholes," Fuel, vol. 265, Article ID 117006, 2020.

[25] H. Guo, Z. Cheng, K. Wang, B. Qu, L. Yuan, and C. Xu, “Coal permeability evolution characteristics: analysis under different loading conditions," Greenhouse Gases: Science and Technology, vol. 10, no. 2, pp. 347-363, 2020.

[26] L. Yuan, "Strategic thinking of simultaneous exploitation of coal and gas in deep mining," Journal of China Coal Society, vol. 41, no. 1, pp. 1-6, 2016.

[27] Z. Wang, Y. Sun, Y. Wang, J. Zhang, and Z. Sun, “A coupled model of air leakage in gas drainage and an active support sealing method for improving drainage performance," Fuel, vol. 237, pp. 1217-1227, 2019.

[28] J. Xu, X. Z. Song, S. J. Peng et al., "Physical simulation experiment on influence of borehole spacing along the seam on effect of gas drainage," Rock and Soil Mechanics, vol. 40, no. 12, pp. 4581-4589, 2019.

[29] B. Ma, J. Xu, L. R. Liu et al., "Analysis of the effect of the borehole length on the efficiency of coal-bed methane exploitation," Chinese Journal of Rock Mechanics and Engineering, vol. 36, no. 1, pp. 175-185, 2017.

[30] C. L. Zhang, J. Xu, S. J. Peng et al., "Effect of borehole amounts on gas drainage quantity and drainage Time," Journal of China University of Mining \& Technology, vol. 48, no. 2, pp. 287-294, 2019.

[31] G. Wang, H. Xu, M. M. Wu et al., "Study of plastic zone width and sealing length based on different elastic constitutive equations," Rock and Soil Mechanics, vol. 39, no. 7, pp. 2599-2608, 2018.

[32] F. B. Zhou, Y. N. Sun, H. J. Li et al., "Research on the theoretical model and engineering technology of the coal seam gas drainage hole sealing," Journal of China University of Mining \& Technology, vol. 45, no. 3, pp. 433-439, 2016.

[33] P. Liu, Y. D. Jiang, and B. X. Fu, "A novel approach to characterize gas flow behaviors and air leakage mechanisms in fracture-matrix coal around in-seam drainage borehole,"
Journal of Natural Gas Science and Engineering, vol. 77, Article ID 103243, 2020.

[34] Z. F. Wang, Y. Zhou, Y. N. Sun et al., "Novel gas extraction borehole grouting sealing method and sealing mechanism," Journal of China Coal Society, vol. 40, no. 3, pp. 588-595, 2015.

[35] Y. Zhang, Q. Zou, and L. Guo, "Air-leakage model and sealing technique with sealing-isolation integration for gas-drainage boreholes in coal mines," Process Safety and Environmental Protection, vol. 140, pp. 258-272, 2020.

[36] C. Zheng, M. Kizil, Z. Chen, and S. Aminossadati, "Effects of coal damage on permeability and gas drainage performance," International Journal of Mining Science and Technology, vol. 27, no. 5, pp. 783-786, 2017.

[37] J. X. Zhang, B. Li, and Y. N. Sun, "Dynamic leakage mechanism of gas drainage borehole and engineering application," International Journal of Mining Science and Technology, vol. 28, pp. 505-512, 2018. 